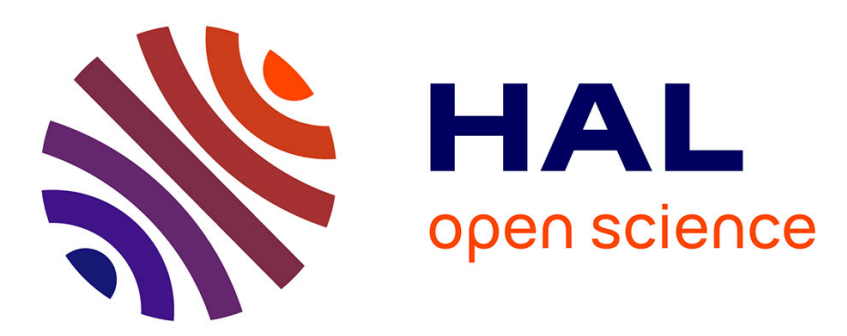

\title{
Société rurale et réaménagement agricole dans le Ségala tarnais \\ Georges Bertrand
}

\section{To cite this version:}

Georges Bertrand. Société rurale et réaménagement agricole dans le Ségala tarnais. Revue Géographique des Pyrénées et du Sud-Ouest, 1962, 33 (2), pp.137-161. 10.3406/rgpso.1962.2065 . hal02570340

\section{HAL Id: hal-02570340 \\ https://hal.science/hal-02570340}

Submitted on 12 May 2020

HAL is a multi-disciplinary open access archive for the deposit and dissemination of scientific research documents, whether they are published or not. The documents may come from teaching and research institutions in France or abroad, or from public or private research centers.
L'archive ouverte pluridisciplinaire HAL, est destinée au dépôt et à la diffusion de documents scientifiques de niveau recherche, publiés ou non, émanant des établissements d'enseignement et de recherche français ou étrangers, des laboratoires publics ou privés. 


\section{Société rurale et réaménagement agricole dans le Ségala tarnais}

\section{Georges Bertrand}

\section{Résumé}

Dans le Ségala tarnais, la structure de la société rurale (masse de moyens et petits exploitants sans disponibilités financières, isolement matériel et psychologique en partie lié à l'habitat dispersé, persistance du faire-valoir direct) est, pour une large part, responsable de la crise agricole (maintien de la polyculture traditionnelle assurant une place trop large à l'autoconsommation, exode rural). Les exploitations bien équilibrées sont rares (16\% du total environ). La masse des petits et moyens exploitants (50 $\%$ du total) se trouve dans une situation critique. Toute tentative de réaménagement doit porter sur cette catégorie. Cependant, le reboisement progresse ; il favorise l'abandon des terres sans, pour l'instant, offrir de compensation.

\section{Citer ce document / Cite this document :}

Bertrand Georges. Société rurale et réaménagement agricole dans le Ségala tarnais. In: Revue géographique des Pyrénées et du Sud-Ouest, tome 33, fascicule 2, 1962. pp. 137-161;

doi : https://doi.org/10.3406/rgpso.1962.2065

https://www.persee.fr/doc/rgpso_0035-3221_1962_num_33_2_2065

Fichier pdf généré le 05/04/2018 


\section{SOCIÉTÉ RURALE ET RÉAMÉNAGEMENT AGRICOLE DANS LE SÉGALA TARNAIS \\ par Georges BERTRAND}

Depuis plus d'un siècle, la situation agricole des hautes et rudes terres du Sud-Ouest du Massif Central ne fait que se dégrader, alors que plus de $80 \%$ de la population continue à y vivre de l'agriculture (1). Il s'agit moins d'une erise brutale que d'un fléchissement progressif, aggravé par la deuxième guerre mondiale. En effet, avec leur climat humide et froid, leurs sols acides, les « Montagnes » (2) du Tam font de plus en plus figure de région répulsive. Depuis 1851, elles ont perdu 50 à $60 \%$ de leurs effectifs. Isa population qui se maintient sur place, environ 30000 personnes sur 180000 hectares, ne le fait en cénéral qu'au détriment de son niveau de vie, car l'exode rural n'a pas encore permis de trouver un nouvel équilibre. Partout, la zone cultivée se rétracte, envahie par les landes et les bois, des hâtiments tombent en ruine et des chemins d'exploitation s'effacent. I a crise agricole est d'ailleurs aggravée par l'instabilité des activités complémentaires, que ce soit l'extraction minière à Peyrebrune, Alban et Montredon (3), ou l'industrie textile qui anime les bourgs de Roquecourbe, Vabre et Brassac.

Cependant, depuis deux ou trois ans, des personnalités locales et des organismes professionnels commencent à s'inquiéter de cette situation. Il s'est créé une Association sylvo-pastorale tarnaise qui

(1) Consulter la carte au $1 / 50000$ (feuilles Castres et Realmont). J'adresse mes vifs remerciements à $M$. Simon RAgy, maire de Montredon, conseiller général, qui a bien voulu me tenir au courant de l'evolution de sa rógion. De larges eniprunts ont été faits au travail inedit de $\mathrm{M}^{\mathrm{me}} \mathrm{Cl}$. Bertrand-Iagarde : Le rayonnement de Castres.

(2) * Montagne $ఎ$, « région montagnole $\bowtie$ : termes locaux couramment utilises. Par Montagne du Tarn, ou Segalas tarnais, nous entendons l'ensemble des terres cristallines qui sostendent dans la partie est du département du Tarn, du Ségala a'bigeois au versant nord de la Montagne Noire (carte 1). Pour la superficie et la population voir Peyooter (8). (Les numéros renvoient à la bibliographie in fine).

(3) Peyrebrune : plomb et zinc (Peñaroya); Alban : spath-fluor (Ugine); Montredon : wolfram (Société des Mines de Salsigne). Cette dernière a fermé en 1961. Voir G. Bertrand (4). 
sf: propose de réaménager toute la région en l'orientant vers le reboisement et l'élevage ovin (4). Mais ce programme n'a suscité que peu d'intérêt et les capitaux, forcóment extérieurs à la régien, sont encore à trouver. Enfin, en 1959, la Chambre d'Agriculture du Tarn a fait procéder à une enquête danss toutes les régions monta-

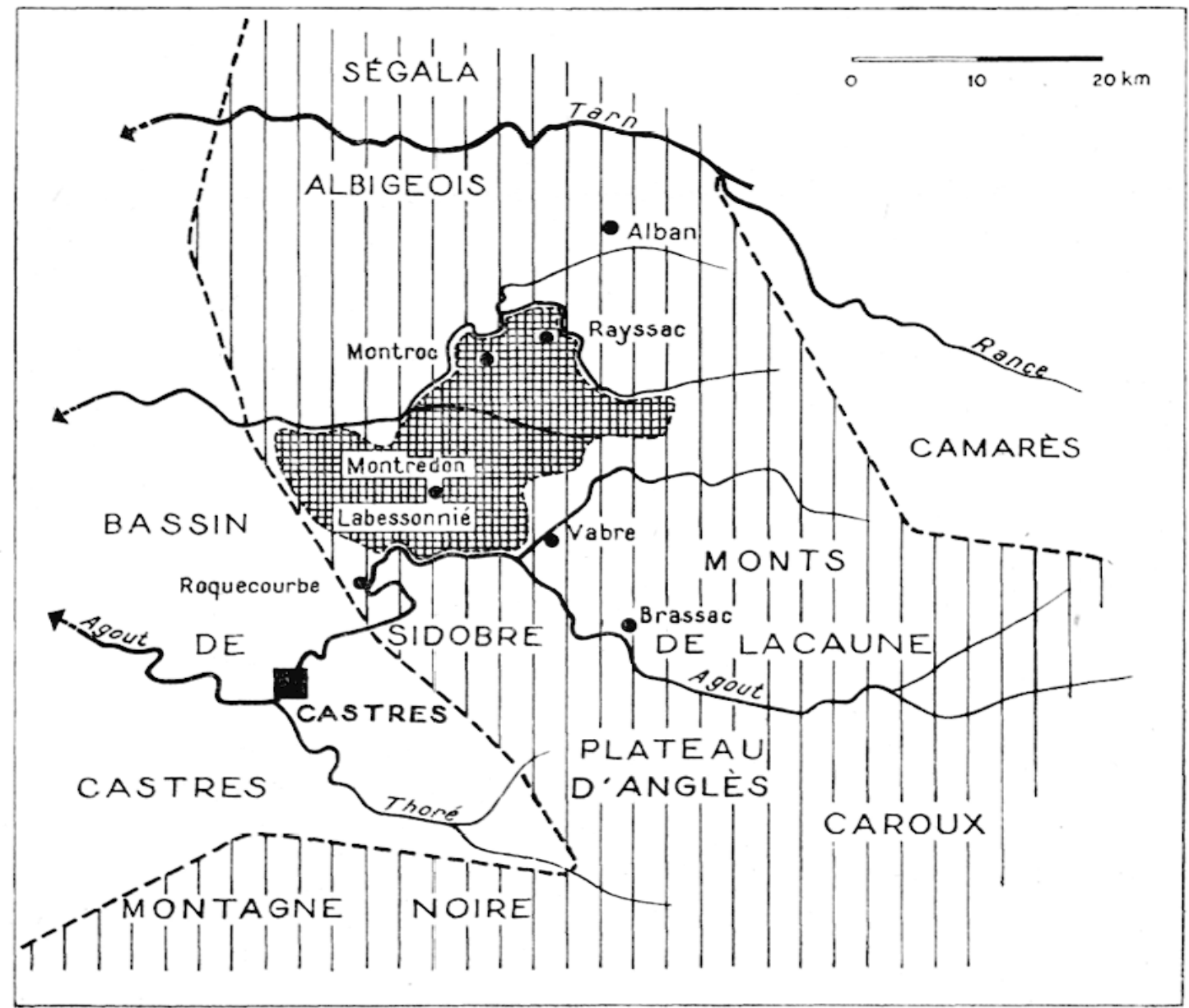

Fig. 1

Les montagnes du Tarn. Croquis de localisation.

En hachures, terrains cristallins. - La région étudiéc est en quadrilré.

gncuses (5). Elle a constaté la décadence de l'agriculture et a préconisé, timidement, quelques palliatifs.

On se propose ici de présenter quelques-uns des problèmes qui se posent dans le canton de Montredon-I uabessonnié (fig. 1). C'est un

(4) G. De Rovville (9).

(5) Peyroutet (8). 
plateau monotone de schistes qui s'élève progressivement au-dessus du bassin de Castres, de $350 \mathrm{~m}$ à $750 \mathrm{~m}$, et qu'entaillent avec vigueur l'Agout et le Dadou (6). Ises quatre communes qui forment le Montredonnais (Arifat, Montroc, Rayssac et surtent Montredon) s'étendent sur 17500 ha et glompent 3574 habitants, scit une densité de 20 au kilomètre carré (7). I e but de ce travail est de rechercher les causes du retard agricole et de montrer les passibilités de réaménagement, en tenant compte de la situation des différentes catégories d'agriculteurs.

I. UNE SOCIÉTÉ RURALE FN VOIE DE DÉGRADATION.

On retrouve dans le Montredonnais tous les caractères d'une société rurale en plein démantèlement : rentabilité insuffisante du système de culture, abandon des terres, effondrement démographique.

1. L'isolement des agriculteurs. - Il ewt à la fois matériel et psychologique. Il faut en chercher les origines dans les condition:s naturelles et historiques qui ont présidé à l'élaberation de la société.

A. Le cloisonnement intérieur. - Mis à part le bourg de Labessonnié (709 hab.) et les centres communaux de Rayssac ( 80 hah.) et. de Montroc (45 hab.), la ponulation se disperse dans des fermes ou dans de minuscules hameaux (8) (fig. 2).

\begin{tabular}{|c|c|c|c|c|c|}
\hline \multirow{2}{*}{1954} & \multirow{2}{*}{$\begin{array}{l}\text { POPUL. } \\
\text { TOTALE }\end{array}$} & \multirow{2}{*}{ BOURG } & \multicolumn{3}{|c|}{ POPULATION DISPERSEE } \\
\hline & & & TOTAL & Hameaux & Fermes \\
\hline $\begin{array}{l}\text { Nombre de lieux ha- } \\
\text { bités. . . . . . . . . }\end{array}$ & 193 & 1 & 192 & 100 & 92 \\
\hline \% des lieux habités & & & & $52 \%$ & $47 \%$ \\
\hline Nombre d'habitants. & 2581 & 711 & 1870 & 1328 & 542 \\
\hline $\begin{array}{l}\% \text { du nombre d ha- } \\
\text { bitants. . . . . . . }\end{array}$ & $100 \%$ & $27,5 \%$ & $72,5 \%$ & $51,5 \%$ & $21 \%$ \\
\hline
\end{tabular}

(6) G. Bertrand (5).

(7) Recensement de la population 1954.

(8) M. Picrre Bozon a analisé un type très voisin de société rurale dans La vie rurale en Vivarais, Thèse Lettres Clermont Ferrand, 1961, 641 p. Voir pp. 205-220 et 468, carte 2. 
Cette dispersion, accquise dès l'époque médiévale, s'est accentuéc pendant le XVIII siècle où, scus la pression démographique, le Platcau a été totalement défriché (9). Les hameaux, plus nombreux que les fermes, groupent $52 \%$ de la population. Ils comportent en moyenne 2 à 4 explo:tations, soit un: douzaine de personnes. Wan:;

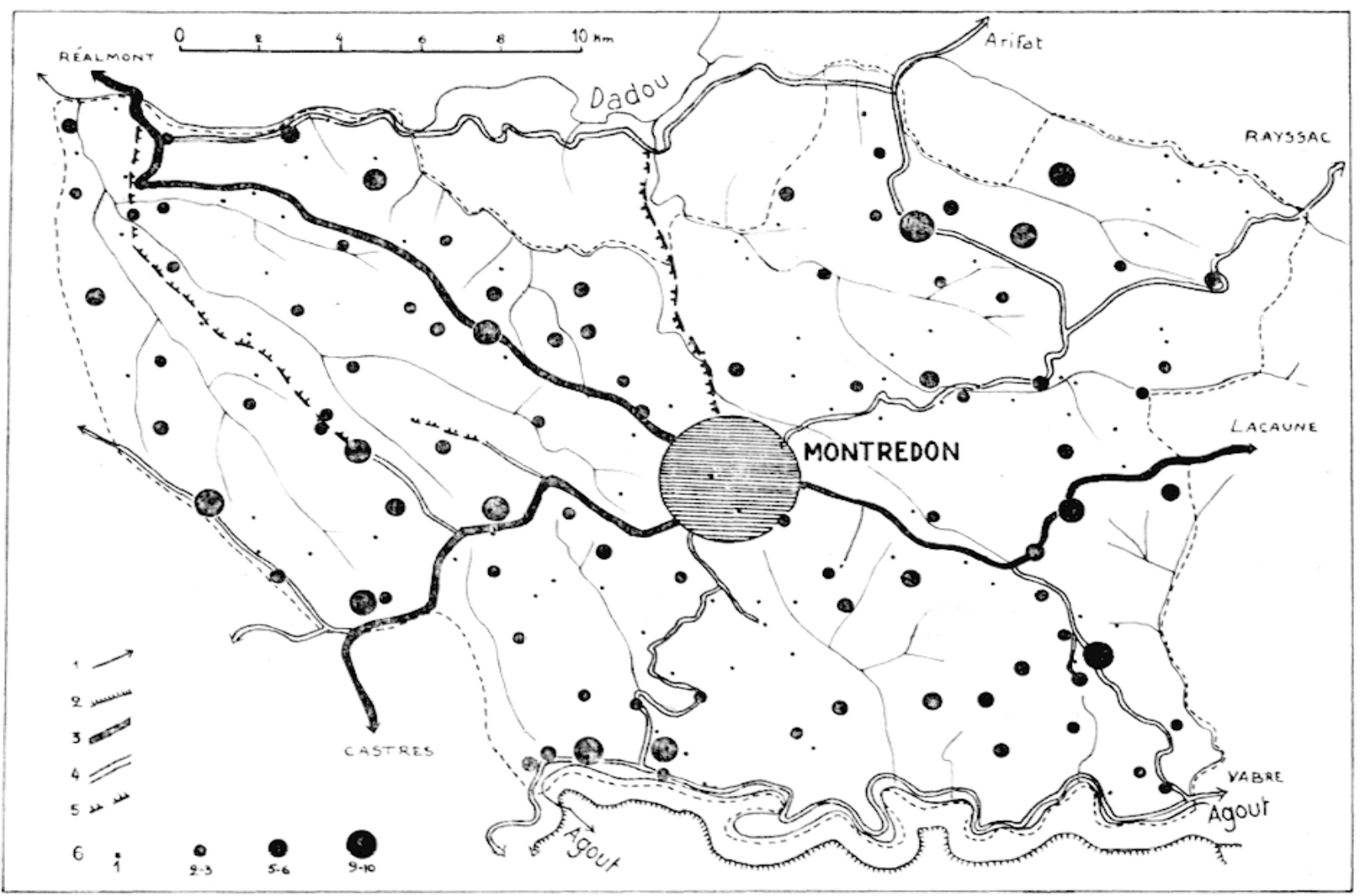

FIG. 2

L'éparplllement des centres d'exploitation agricole dans la région de Montredon.

1. Cours d'eau. - 2. Voie ferrée Castres-Murat. - 3. (irandes routes. - 4. Routes secondaires. - 5. Routes non foudronnées. - La limite de la commune est en tireté. - Les cercles noirs représentent le nombre de feux. selon l'échelle qui figure sur le croguis.

les plus importants (20 à 30 habitants), il y a quelques petits commerçants ou artisans (épicerie-mercerie-buvette-tabac, dépôt de butagaz, forgeron-mécanicien); mais toutes ces activités tendent à disparaître devant la concurrence du bourg. Le hameau est un simple

(9) Les principales fermes et les gros hameaux actuels correspondraient aux 11 flefs, aux 2 biens emphytéotiques et aux 2 alleux que comportait la baronnie de Montredon en 1255 (d'après F. Bovsouet) (5). Sur la carte de Cassini, on releve 160 lieux-dits sur les 192 qui existent de nos jours dans la commune de Montredon. 
assemblage $\mathrm{d}$ 'exploitations agricoles et doit être considéré, au même titre que la ferme, comme une forme de dispersion (10). Cet éparpillement des centres d'exploitation s'accompagne d'un morcellement des finages en petites parcelles (50 à 90 ares) souvent éloignées les unes des autres et cloisonnées par un bocage léger, de type hérupe (11). La mécanisation $n$ 'est pas rentable sans remembrement mais, à part quelques regroupements de terres à l'amiable et quelques arrachages de haies, rien n'a été fait dans ce sens.

Les difficultés de communication accentuent les effets de la dispersion. Fermes et hameaux se raccordent aux routes goudronnées par de longs chemins défoncés. Les minces interfluves où se localisent l'habitat et les cultures sont isolés par des gorges de 100 à $200 \mathrm{~m}$ de profondeur. Les routes suivent les lanières de plateau orientées Est-Oucst et il $n$ 'Y a pas d'axe de circulation Nord-Sud (12). Aux obstacles topographiques s'ajoute le mauvais état des chemins vicinaux que les budgets communaux, de plus en plus déséquilibrés; par l'exode rural, ne permettent plus d'entretenir. Le canton compte $483 \mathrm{~km}$ de chemins vicinaux, soit $1 \mathrm{~km}$ pour 7,5 habitants. L'éloignement impose souvent l'achat $d$ 'un véhicule automobile, qui grève les budgets et retarde l'achat du tracteur (il y a autant d'automobiles que de tracteurs). Si on ne tient pas compte du bourg, il y a un téléphone pour 151 habitants, soit un abonné tous les $9 \mathrm{~km}^{2}$. Certains, qui sont situés au fond des vallées, vivent dans une véritable solitude.

Enfin, l'équipement du bourg s'avère insuffisant pour assurer le ravitaillement normal de la population. Si les artisans et les commerçants qui travaillent pour l'agriculture sont relativement nombreux (graineterie, vente d'engrais, matériel de culture), les magasins d'alimentation sont rares, ce qui souligne le rôle de l'auto-consommation dans les campagnes voisines. I es commerces fixes sont complétés, el concurrencés, par des marchands forains qui, chaque lundi, installent leurs éventaires sur le foirail. Cependant beaucoup d'achats nécessitent des déplacements à Castres $(25 \mathrm{~km})$ et Albi $(30 \mathrm{~km})$. Toici 50 ans, Iabessonnié avait des foires à bestiaux réputées. Elles sont actuellement en complet dérlin à eause de la concurrence des foires de Castres, Réalmont et surtout Puylaurens (13). Tses marchands de

\footnotetext{
(10) \& Le hameau est autre chose qu'un modele réduit de village. Il compte en génèral un peuplement agricole, il ne possède pas les cadres sociaux et professionnels qui caractérisent le village ». M. Chrvinik, La vie humaine dans les Pyrénées ariegeoises. Thèse Lettres Toulouse, 1954, pp. 155-156.

(11) Photographies aćriennes I. G. N., 1948, Missions Lavaur-Castres, LacauneBédarieux, et Gaillac-Réalmont.

(12) Montroc et Saint-Paul-l'Eglise sont distants, en ligne droite, de 2,5 km, mais il faut parcourir par la route $10 \mathrm{~km}$.

(13) En 1956, les transactions n'ont porté que sur 2590 animaux dont 950 porcelets, 786 ovins, 611 veaux, etc.
} 
bestiaux vont acheter les animaux dans les fermes et peuvent ainsi mieux imposer leur prix. L'équipement bancaire se réduit à une petitc agence de la Banque Populaire du Tarn et de l'Aveyron et à une succursale du Crédit $\Lambda$ gricole, permanente depuis 1958. Le bourg, insuffisamment équipé, ne peut pas être considéré comme un élément favorable au progrès agricole et à la cohésion sociale.

L'individualisme reste le trait dominant de la population. Il s'accommode mal des mouvements syndicaux et coopératifs. Le Syndicat de défense professionnelle des exploitants de la commune de Montredon ne groupe que 70 mombres. En 1956, le chiffre d'aftaires de la Coopérative agricole de Montredon et d'Arifat n'a pas dépassé 1,2 million d'anciens franes. La profession agricole n'est pas organisée. On voit done mal comment l'agr:culture pourrait progresser. Il faudrait que l'impulsion vienne de l'extérieur.

B. L'insuffisance des relations avec i'extérieur. - La voie ferrée Castres-Lacaune circule dans la vallée de l'Agout, aucune route ne la relie au Plateau. Elle a joué un rôle néfaste en faisant disparaître les d:ligences et les rouliers qui desservaient le Montredonnais. L'isolement n'a été rompu par les transports routiers que vers 1935. Cependant, le réseau routier dcmeure insuffisant. Deux routes départeinentales venant respectivement de Réalmont et de Castres convergent vers Labessonnié, d'où part une route vers Lacaune. Une seule grande route traverse les communes de Montroc et de Rayssac. Si le bourg est assez bien desservi par les autobus (deux services quotidiens vers Castres et un vers $\Lambda$ lbi il n'en est pas de même des autres centres communaux, qui n'ont pas toujours un service journalier. Le Montredonnais se situe dans un « angle mort » à la limite du rayonnement de Castres, prépondérant dans les communes de Montredon et d'Arifat, et de celui d'Albi qui l'emporte à Rayssac et Montroc. D'ailleurs, l'aide extérieure a toujours été faible. Les difficultés de cette paysannerie inorganisée et pauvre $n$ 'ont guère suscité d'intérêt. Les services publics et les organismes professionnels sont souvent restés dans l'expectative. De plus, les techniciens de la Direction des Services agricoles du Tarn n'ont pas toujours été bien accueillis par les paysans qui, par exemple, $n$ 'ont pas su tirer profit des essais d'engrais et de céréales fait en 1955-1956. Devant cette apathie, la D.S.A., qui ne dispose que d'un personnel réduit, a préféré porter ses efforts vers des régions plus réceptives, la plaine en particulier. On a essayé de remédier à cette situation en dévelcppant l'enseignement agr:cole post-scolaire pour les jeunes de 14 à 17 ans. Les résultats paraissent plus probants chez les filles iarts 
ménagers, couture) que chez les garçons. Le soutien extérieur le plus positif vient du Crédit Agricole. En 1958, la caisse lccale de Montredon a consenti des prêts d'un montant de 122 millions d'anciens franes (14.)

\begin{tabular}{|c|c|c|c|c|c|}
\hline \multirow[b]{2}{*}{ Court terme ( 6 mois renouv.) } & \multirow[b]{2}{*}{42} & \multirow[b]{2}{*}{ emprunts } & \multirow[b]{2}{*}{26} & \multicolumn{2}{|c|}{ Montant moyen } \\
\hline & & & & millions & $625.000 \mathrm{AF}$ \\
\hline Moyen terme (15 ans)..... & 98 & $»$ & 60 & $\gg$ & $610.000 \mathrm{AF}$ \\
\hline Long terme $(30$ ans)... & 42 & $»$ & 36 & $\gg$ & $855.000 \mathrm{AF}$ \\
\hline
\end{tabular}

La moitié des capitaux sont empruntés à moyen terme, en général pour les achats de matériel agricole. Ise montant moyen des prêts, $695000 \mathrm{AF}$, peut sembler lourd pour une région médiocre. Le danger est d'autant plus grave que les prêts sont souvent utilisés pour des dépenses qu'il est difficile d'amortir (entretien de bâtiments, tracteur sur une petite exploitation). C'est pourtant le seul moyen de moderniser l'agriculture.

2. Les insuffisanmes de la polyculture traditionnelle. - La presque totalité de la population, $80 \%$ environ, vit en fonction d'un système polycultural de type familial qui fait une large place à l'autoconsommation. Le maintien de la polyculture est une garantie contre l'irrégularité du climat. Si la moyenne annuelle des pluies est de $783 \mathrm{~mm}$, les extrêmes atteignent $315 \mathrm{~mm}$ et $1540 \mathrm{~mm}$ et les écarts de $50 \%$ avec la moyenne ne sont pas rares (15) (fig. 3). La répartition saisonnière est encore plus capricieuse. In pleine période végétative, de mars à mai, les pluies peuvent représenter de 2 à $20 \%$ de la tranche d'eau annuelle et les pluies d'automne, particulièrement utiles pour le maïs, varient de 1 à 16. Mais la polyculture peut aussi s'expliquer par des causes économiques et sociales : isolement, individualisme, taille réduite des exploitations (18 hectares en moyenne) (16).

Dans ces conditions, l'évolution agricole $\mathrm{n}$ 'a pu être que lente et imparfaite. Vers 1890, le Plateau était encore un Ségala : assolement seigle-jachère, pomme de terre et maïs, écobuage des landes, ovins

(14) Peyrovtet (8).

(15) La station météorologique de Labessonnić n'a fonctionné que de 1820 a 1914.

(16) Comparer, par exemple, avec le Ségala de Naucelle qui a surmonté les difncultés climatiques et s'est orienté vers des speculations rentables. ENJALBERT, $A$ travers le Segala. Notes de geographie historique. Rodez, $1950,63 \mathrm{p}$., et Les limites orientales de la polyculture de type aquilain. Revue géogr. des Pyrénées et du Sud-Ouest, 1945, p. 265. 

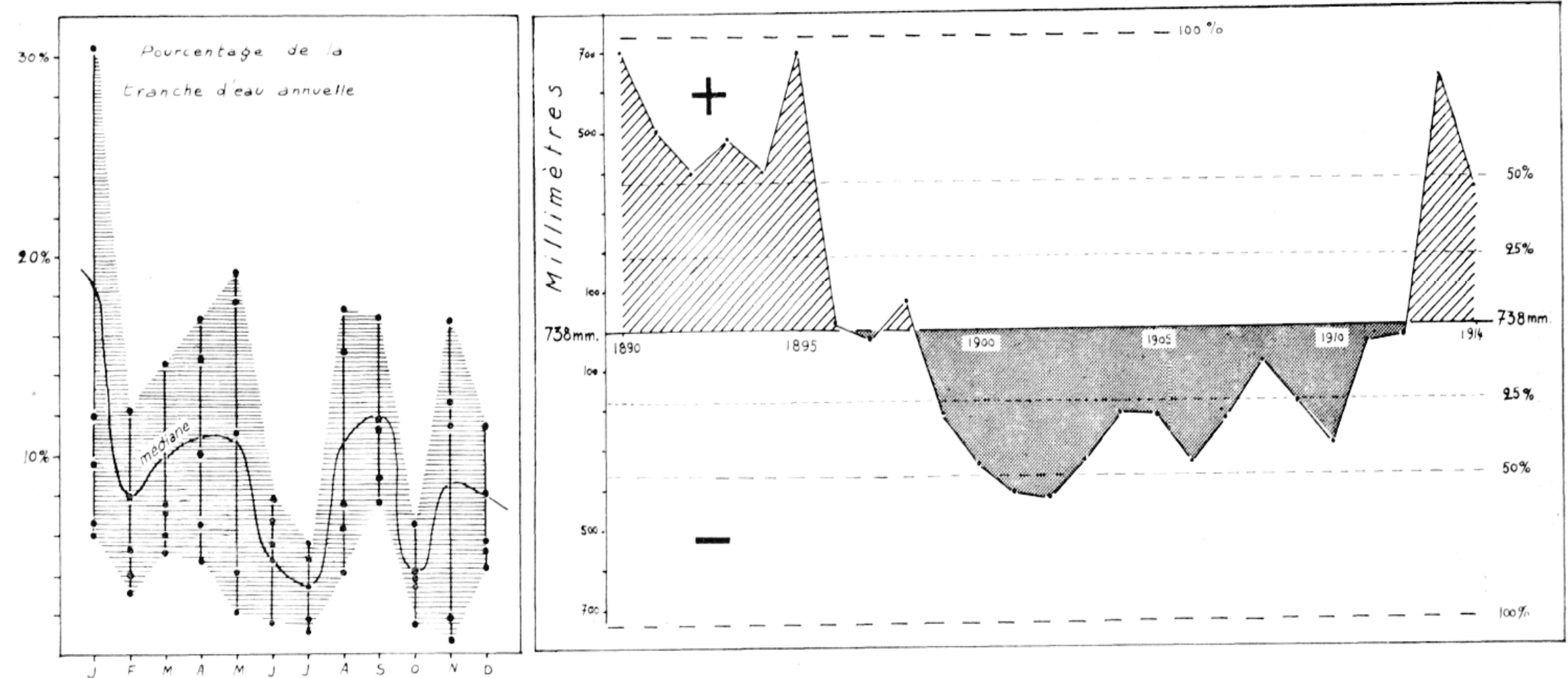

Fig. 3

La variabilité des pluies dans le Montredonnais.

Ecarts par rapport à la moyenne 1890-1914. - A droite, va ialilité interannuelle. - - A gauche, variabilité saisonnière. 
(24 000 têtes en 1850, soit 40 bêtes par habitant) (17). En 1890-1892 la chaux fait son apparition, le blé s'étend et la jachère cède lentement la place aux prairies artificielles. L'élevage bovin ne se développe pourtant qu'à partir de 1945-50. Au fond polycultural traditionnel des Ségalas : seigle, avoine, sarrasin, ovins, pores et un peu de vigne, chaque « révolution » est venue ajouter des spéculations nouvelles : pomme de terre, maïs, blé, prairies artificielles, bovins. Comme aucune production. faute de soins, n'a donné de meilleur résultat que les autres, le paysan montredonnais n'a pas ressenti la nécessité de faire un choix. On aboutit ainsi aux incertitudes de la polyculture actuelle. Cependant, dans ia plupart des cas, l'élevage tend à l'emporter. I ses prairies artificielles couvrent $43 \%$ de la surface cultivée et les cultures fourragères se développent. Les bovins ont pris la première place. Le veau de boucherie constitue la principale production. Cependant le troupeau manque d'homogénéité

\begin{tabular}{|c|c|c|c|}
\hline & $1850-1860$ & $1900-1910$ & $1950-1960$ \\
\hline Bovins. . . . . . & 3000 & 3800 & 4200 \\
\hline Ovins. . . . . . & 24000 & 17000 & 5200 \\
\hline Pores. . . . . . . & 3800 & 6000 & 3500 \\
\hline
\end{tabular}

(aubrac, salers, schwytz, montbéliarde), les conditions sanitaires sont défavorables (en 1956, une enquêtes des Services Vétérinaires a révélé que la tuberculose sévissait dans $77 \%$ des étables) et les croisements industriels (taureaux limousins) n'ont pas toujours donné de bons résultats. $L$ 'élevage des brebis laitières de la race de Lacaune pour la production de pâte à fromage (Roquefort) est beaucoup plus rentable. Mais la traite bi-quotidienne et la garde du troupeau demandent trop de temps. Certains paysans ont préféré s'orienter vers la production de l'agneau gris et du «mouton albigeois » (18).

Les cultures se maintiennent malgré la faiblesse des rendements. C'est le cas du blé (47\% de la surface consacrée aux céréales, 1691 ha). Les engrais sont insuffisants en quantité et souvent mal choisis (acidification des sols). Par contre le chaulage est trop abondant, quoique irrégulier. Cependant, les assolements présentent

(17) Les chiffres cités sont ceux des différents Recensements agricoles.

(18) Mouton maigre que l'on vend aux agriculteurs de la Plaine qui pratiquent l'embouche; les animaux gras sont ensuite expédiés dans les villes du Midi méditerranéen. 
un meilleur équilibre (hlé-avoine-pomme de terre-prairie artificielle pâturée la seconde année;. La motorisation, on le verra plus loin, réalise des progrès considérables, qui sont malheureusement suivis de trop loin par la mécanisation. Le travail humain conserve done une grande importance. La polyculture ne laisse aucun répit au paysan qui n'en retire pourtant que de médiocres bénéfices. Toutes les conditions sont remplies pour faire du Montredonnais une région d'émigration.

3 L'exode rural (fig. 4). - L'équilibre entre la population et les ressources semble avoir été toujours précaire. De 1801 à 1851, la population a augmenté de $36 \%$ et n'a été sauvée de la disette que grâce à la pomme de terre. L'émigration saisonnière a permis de conserver des densités de 80 à 85 habitants au $\mathbf{k m}^{2}$ cultivable. Après 1890, le développement des centres urbains et industriels de la plaine a entrainé un abandon massif. Le Montredonnais a perdu $55 \%$ de ses habitants, émigrés vers Castres et sa région

\begin{tabular}{|c|c|c|c|}
\hline 1956 & NAISSANCES & DECES & EXCEDENT \\
\cline { 2 - 4 } & $18,4 \%$ & $12,4 \%$ & $6 \%$ \\
\cline { 2 - 4 } Moyenne française & $12,3 \%$ & $10,4 \%$ & $1,9 \%$ \\
Montredon. . . . . & $12,3 \%$ \\
\hline
\end{tabular}

textile $(69 \%)$, Albi $(16 \%)$, le Bas-Languedoc $(8,4 \%)$. Il s'y ajoute l'effondrement de la natalité qui est passée de 26,4 \% en 1801-1852 à $10,4 \%$ en 1951-1957. Bien que la mortalité ait baissé, le croît naturel n'est que de $1.9 \%$. I a densité est tombée à $20 \mathrm{hab} . / \mathrm{km}^{2}$. En réalité, la densité agricole est plus faible car beaucoup de jeunes domiciliés dans le canton vont travailler à Roquecourbe, Réalmont ou Vabre (19). De toute manière, les jeunes de mo:ns de 20 ans ne représentent plus que $21,7 \%$ de la population et le vieillissement des chefs d'exploitation constitue un obstacle à la modernisation : $38 \%$ ont plus de 60 ans et $1,3 \%$ seulement ont moins de 30 ans. Le maintien de la polyculture donne l'impression que l'on manque de personnel. En réalité, si on observe la répartition de la maind'œuvre par exploitation (fig. 7), on se rend compte qu'elle est souvent surabondante et presque toujours mal utilisée (travailleurs médiocres, âgés ou non qualifiés, dont le nombre supplée la qualité).

(19) Chaque jour un autobus conduit une trentaine de jeunes files aux ateliers de bonneterie de Hoquecourbe. 
La situation dès autres secteurs de la Montagne du Tarn est à peu près semblable (20). Les problèmes agriccles $\mathrm{y}$ sont les mêmes et l'émigration est partout aussi forte. Toute la société « montagnole» est en crise. On y découvre cependant quelques spécialisations originales. Les Monts de Lacaune se consacrent à l'élevage ovin laitier pour Roquefort et à la charcuterie semi-industrielle, qui a acquis une excellente réputation dans tout le Midi. Les habitants du Sidobre

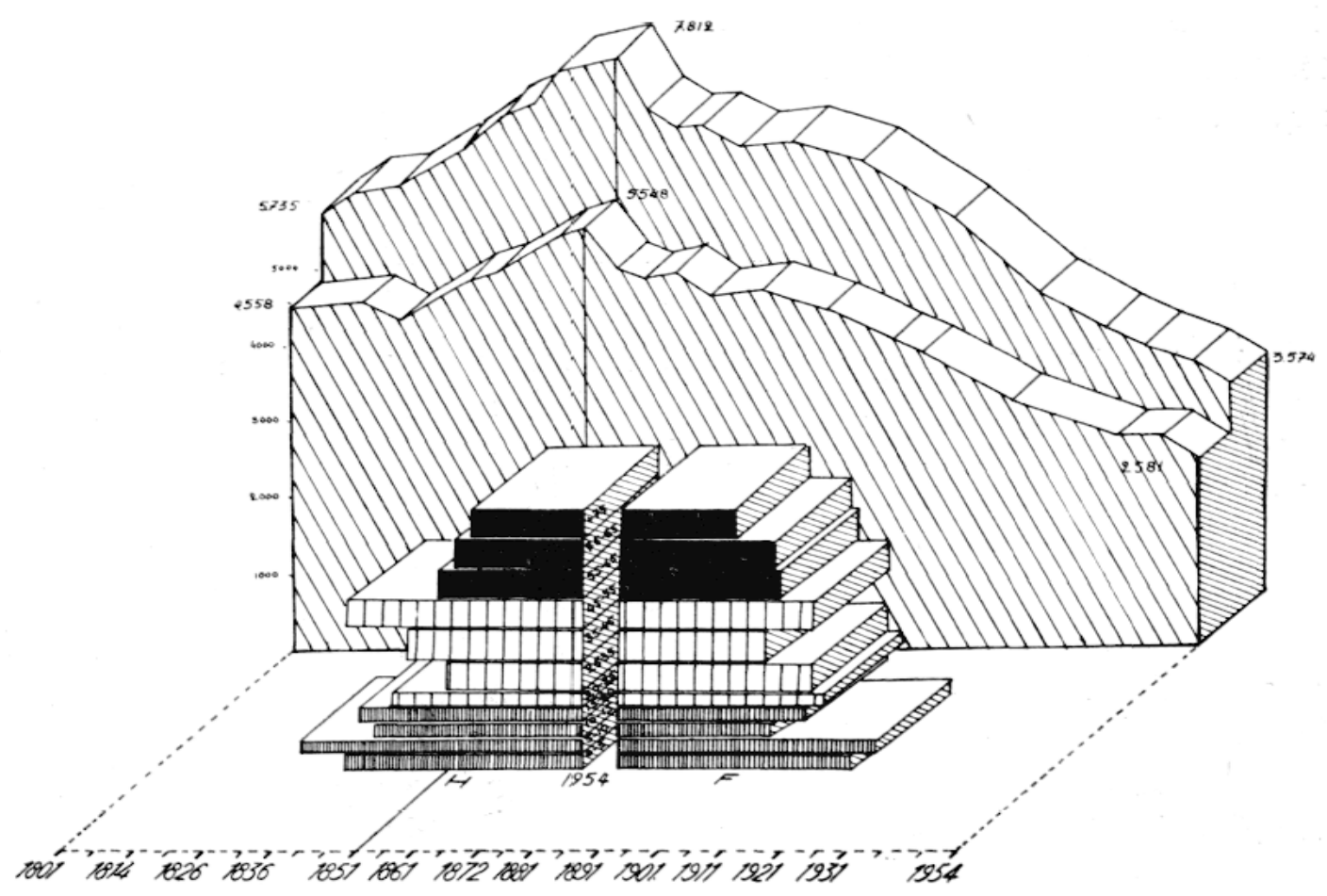

FiG. 4

Evolution de la population de 1801 à 1954 et pyramide des âges 1954 dans le Montredonnais.

ont pratiquement abandonné l'agriculture pour extraire et travailler le granite. Cette industrie, fort lucrative, a ranimé le vieux village de Lacrouzette. Sous l'impulsion des industriels lainiers mazamétains, le versant nord de la Montagne Noire et le Plateau d'Anglès se sont tournés vers l'élevage de vaches laitières schwytz ou vers l'élevage à l'étable d'animaux de boucherie (avec ensilage du foin vert). Enfin,

(20) Il n'y a pas d'études récentes de géographie rurale. Signalons cependant : A. DAvid, La Monlagne Noire, 1929; J. RoY, La Montagne de l'Espinouse. Ann. de Géotraphie, 1931; A. MaYNADIER, Le Sidobre, 1934, 187 p. dactyl.; S. Asalric, La vie rurale dans la vallèe du Thoré. Rev. géogr. Pyrénées Sud-Ouest, 1937, pp. 214-236; G. Galrmert, Introduction d l'étude de la giographie humaine du Plateau d'Angles. Ibid., 1950, pp. 160-177. Voir aussi H. Enjalbert (note 16). 
les Ségalas de V'alence et de Villefranche-d'Albigeois sont davantage restés fidèles aux formes traditionnelles de l'élevage bovin et des cultures céréalières. Mais, partout, il ne s'agit que de solutions assez limitées qui n'intéressent qu'une partie, souvent réduite, de la population. Le reboisement est la seule révolution d'ensemble qui bouleverse à la fois l'économie et le paysage. I ses plantations de pins et de sapins, environ 15000 ha, ont submergé le versant nord de la Montagne Noire, le Sidobre, le Plateau d'Anglès et de larges secteurs de la région de Lacaune. Les paysans du Montredonnais ne sont pas restés tout à fait insensibles à ces sollicitations souvent contradictoires. Chaque catégorie d'exploitants a réagi selon ses possibilités.

\section{LASS POSSIRIIITÉs DF REAMAENAGEMFNT.}

1. Les catégories sociales. - Dans cette région presque uniquement agricole, la propriété et l'exploitation du sol constituent les bases essentielles de distinction sociale. Malheureusement, il $\mathbf{n}$ 'a pas été possible d'établir un tableau des catégories d'exploitants en tenant compte des budgets d'exploitation. Ie système polycultural montredonnais est trop complexe et les prélèvements de l'autoconsommation sur la production ne peuvent pas être déterminés avec suffisamment de précision. Ises intéressés eux-mêmes, comme tous les petits polyculteurs, ont une conception étriquée de la comptabilité agricole dans laquelle $n$ 'interviennent ni la rémunération du travail familial, ni les produits consommés sur place. A une ou deux exceptions près les paysans ne dressent pas de véritables budgets d'exploitation et leur caractère volontiers soupconneux n'est pas pour faciliter une telle enquête. Dans ces conditions, il a fallu recourir à une méthode moins rigoureuse.

A. Les seuils d'exploitation (21). - On a utilisé les fiches individuelles du Recensement agricole de 1956, après en avoir contrôlé un certain nombr: par enquête directe (22). Parmi la masse de

(21) L'expression « seuil d'exploitation $\gg$ n'est guère satisfaisante. On avait pensé a \& seuil de rentabilite $\gg$ mais il $y$ : avait confusion possible avec une étude de comptabilité agricole.. Enfin on a cru devoir renoncer à l'expression * seuil d'exploitabilité » pourtant plâs expressive.

(22) Le Recensement agricole individuel de 1956 est loin d'être parfait; il fourmille d'inexactitudes, en particulier pour les produits animaux. On peut aussi lui reprocher d'avoir vieilli. Il est cependant utilisable, à condition de faire de nombreux recoupements et de laisser de côté certaines rubriques. C'est le seul moyen davoir des renseignements sur chaque exploitation. Nous remercions $M$. le Directeur de I'I.N.S.E.E. à Toulouse d'avoir bien voulu nous laisser utiliser les fiches individuelles a la condition d'en conserver l'anonymat. 
renselgnements foumis, on a choisi les facteurs les plus caractéristiques du syrstème agricole. (irâce à ces critères, il a été possible d'établir sept graphiques qui, analysés et comparés, révèlent l'existence de « seuils » à partir desquels les exploitations changent de caractère. Ise critère le plus signiticatif est celui de la motorisation, si l'on tient compte à la fois du rapport nombre de chevaux/superficie et du rapport méranisation/motorisation. Sur ce terroir aux pentès fortes, aux sols lourds, aux parcelles éloignnées et aux chemins mal cntretenus il faut un tracteur puissant et rapide d'au moins 21 à $25 \mathrm{CV}$. Une enquête directe serrée montre que de tels engins, cô̂teux à l'achat et à l'entretien, cessent d'être rentables dans une exploitation de polveulture inférieure à une vingtaine d'hectares. De plus, beaucoup de petites exploitations n'ont pas de train de culture et le tracteur apparait ainsi comme une sorte de luxe mural. (Y'est seulement dans les exploitations de plus de 35 ha que l'on trouve un équipement assez complet. (pulvérisateurs, polysocs, épandeur d'engrais etc). Le rapport céréales/prairies artificielles permet de noter l'orientation du système de culture et de découvrir les premières tentatives de spécialisation. I'élevage, première source de revenus, mérite une attention particulière. I'analyse du rapport ovins/hovins conduit à d'importantes constatations : les deux élevages sont en général menés de front, il n'y a pas d'ovins au-dessous de 18 hectares et les grosses rrmades n'apparaîssent qu'à partir de $3 \bar{i}$ ha. Cette limitation de l'élevage ovin doit être soulignée car il s'agit d'une ressource particulièrement intéressante. Le lait de brebis est payé 110 anciens franes le litre, l'agneau gris et le « nouton albigeois » se vendent bien. Le développement de l'élevage cst lié au rapport prairies artificielles/prés naturels et son caractère plus ou moins intensif ressort du rapport bétail (ovins et bovins)/prairies artificielles.

Ises problèmes d'emploi de main-d'œuvre (productivité, influence de la motorisation sur l'utilisation de la main-d'œuvre, charge humaine des exploitations) apparaissent si on établit le rapport maind'œuvre (familiale et salariée) avec ou sans tracteur/personnes non actives. Deux seuils apparaissent avec netteté : l'un vers 35 ha, qui sépare les petites exploitations familiales surchargées et mal équipées des grasses exploitations agricoles. Fnfin, il a été tenu compte de l'âge des exploitants et du pourcentage des abandons par catégorie pour la période 1951-1955. Ainsi, quatre seuils ont été déterminés : $6,18,35$ et 60 ha. I a superficie joue un rôle d'autant plus important quc toutes les exploitations ont, en gros, le même système de culture. On en arrive ainsi à distinguer cinq catégories sociales. 


\begin{tabular}{|c|c|c|c|}
\hline CATEGORIES & HECTARES & $\begin{array}{c}\text { NOMBRE } \\
\text { D'EXPLOITAT. }\end{array}$ & $\%$ DU NOMBRE \\
\hline Micro-exploitants. . . . . & $1-5$ & 34 & 9,4 \\
\hline Petits exploitants.... & $6-18$ & 158 & 43,5 \\
\hline Moyens exploitants... & $19-35$ & 95 & 26,1 \\
\hline Gros exploitants. ..... & $36-60$ & 51 & 14,1 \\
\hline Très gros exploitants.. & $61-120$ & 24 & 6,6 \\
\hline
\end{tabular}

Il reste cependant à tenir compte du régime de la propriété.

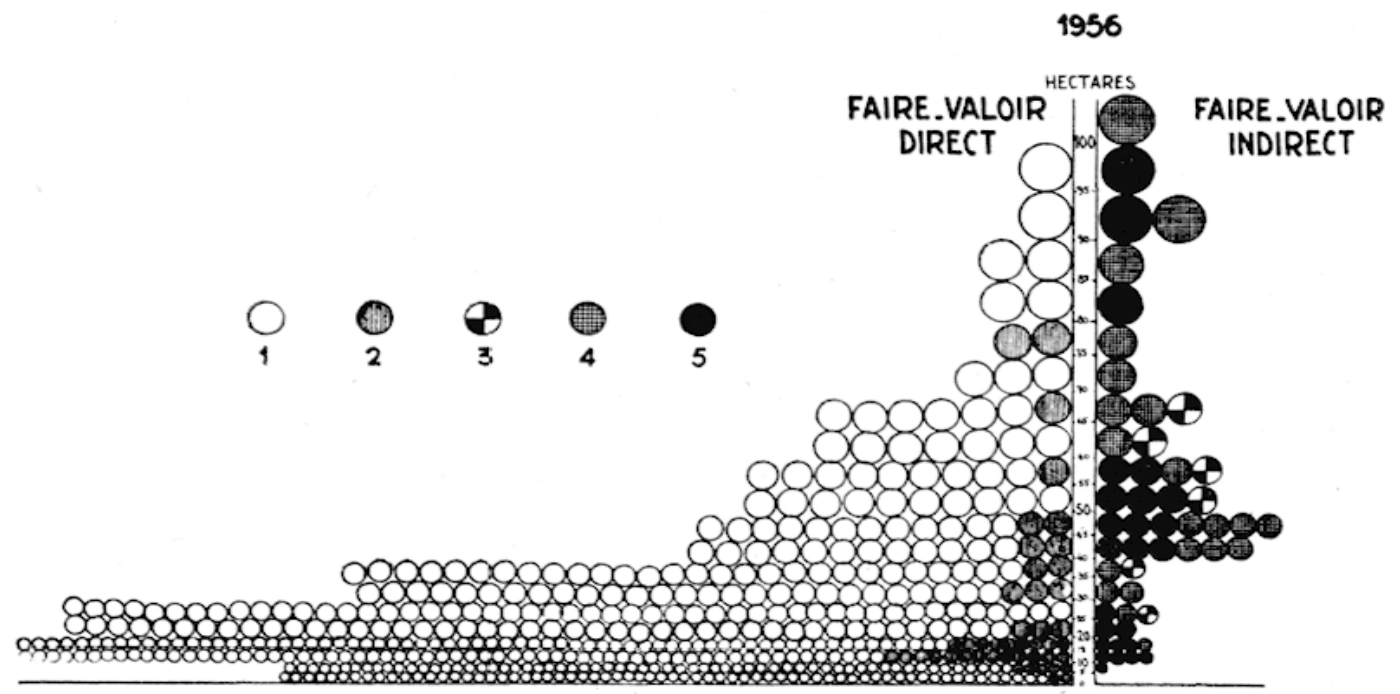

Fra. 5

\section{Pyramide des exploitations et structure sociale en 1956 (commune de Montredon).}

1. Faire-valoir direct pur. - 2. Faire-valoir direct avec location de parcelles. - 3. Maître-valetage. - 4. Métayage. — 5. Fermage.

B. Les propriétaires exploitants. - La société rurale montredonnaise est essentiellement formée de petits et moyens propriétaires (fig. 5). Le faire-valoir direct intéresse $90,5 \%$ des exploitations et $84 \%$ de la surface totale (23).

(23) Nous considérons comme propriétaire exploitant celui qui cultive direcetement sa terre, même sil a pris en location une partie de celle-ci, à condition que la surface louée ne dípasse pas celie qui lui appartient. Par contre, le maitreval tage - qui est souvent considéré comme du faire-valoir direct - sera étudié avec I exploitation indirecte dans la mesure où celui qui cultive réellement la terre est un salarjé. 
Les micro-propriétés inférieures à 6 ha représentent un peu moins de $10 \%$ du total des exploitations. On les rencontre dans les gros hameaux et autour du bourg de Montredon, qu'elles cernent d'une mosaïque de petites parcelles souvent mal entretenues. Ce sont en général des exploitations à autoconsommation, sans secteur commercialisé. Les plus nombreuses, $60 \%$ environ, sont des exploitations-retraite qui, comme leur nom l'indique, appartiennent à des retraités (vieux salariés agricoles, anciens artisans, vieux propriétáires « retirés » qui ont cédé à leurs enfants, ou vendu, la majeure partie de leur exploitation). I a plupart d'entre eux s'efforcent de maintenir une exploitation de polvculture complète (1 à 2 têtes de gros bétail, quelques prairies artificielles, des labours consacrés aux cultures légumières et parfois au blé, importante basse-cour). Non seulement. le matériel agricole est insuffisant mais encore l'équipement ménager se réduit trop souvent au fourneau à butagaz, quand on ne continue pas à utiliser le feu de bois. Il $y$ a là de véritables taudis muraux. I a disparition de ces retraités entraîne celle de l'exploitation, achetée par les paysans voisins ou, le plus souvent, laissée en friches.

Ises artisans (menuisiers, forgerons), les petits commerçants (merciers) et les employés (facteurs, cantonniers) possèdent de nombreux « biens de village ». Il s'agit ici d'une simple ressource. $d$ 'appoint. La vigne $y$ tient une place $d$ 'honneur; objet de soins constants, elle donne un vin que le propriétaire jaloux peut seul apprécier. Viennent ensuite les légumes de plein champ et, parfois, un peu de grain pour la basse-cour. Beaucoup de biens de village évoluent vers le jardin potager, la majeure partic de l'exploitation demeurant en friche.

Les « mineurs-paysans » représentent 5 à $6 \%$ de la population active (24). T'exploitation agricole, faute de temps et de moyens financiers, est négligée et les rendements sont dérisoires. « Le mineurpaysan voit doubler sa peine mais non son profit... Une grande partie du travail incombe à la femme dont la condition est plus pénible que dans le cas $d$ 'un genre de vie purement agricole 》 (25). Tues sociétés minières tiennent très largement compte de l'appoint agricole et jouent sur le manque de sens syndical pour distribuer des salaires insuffisants, ce qui a pour effet de river le minenr à sa petite propriété.

\footnotetext{
(24) Le genre de vie des mineurs-paysans a déia été etudié : G. Bentrand (4). On se contente de rappe!er ici les conclusions qui interessent l'agriculture.
}

(25) G. Bertrand (4). 

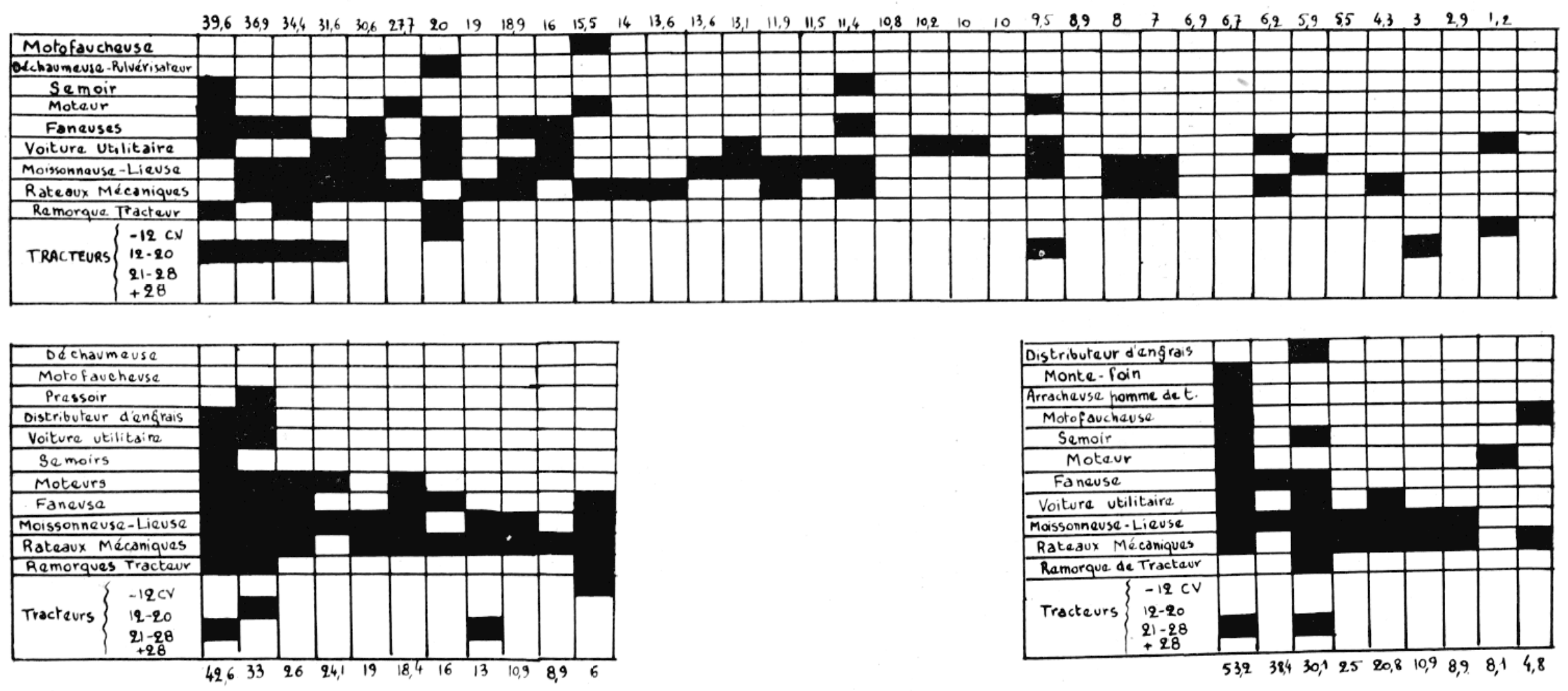

Fig. 6

Motorisation et mécanisation.

Sondages dans les communes de Montredon (en haut), Arifat et Montroc (à gauche), Rayssac (à droite). Les exploitations sont classées d'après leurs superficies. 


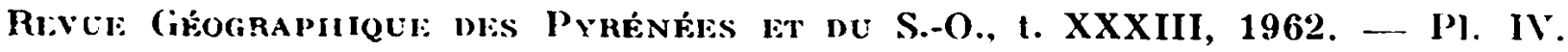

L.e MoNTheorinats

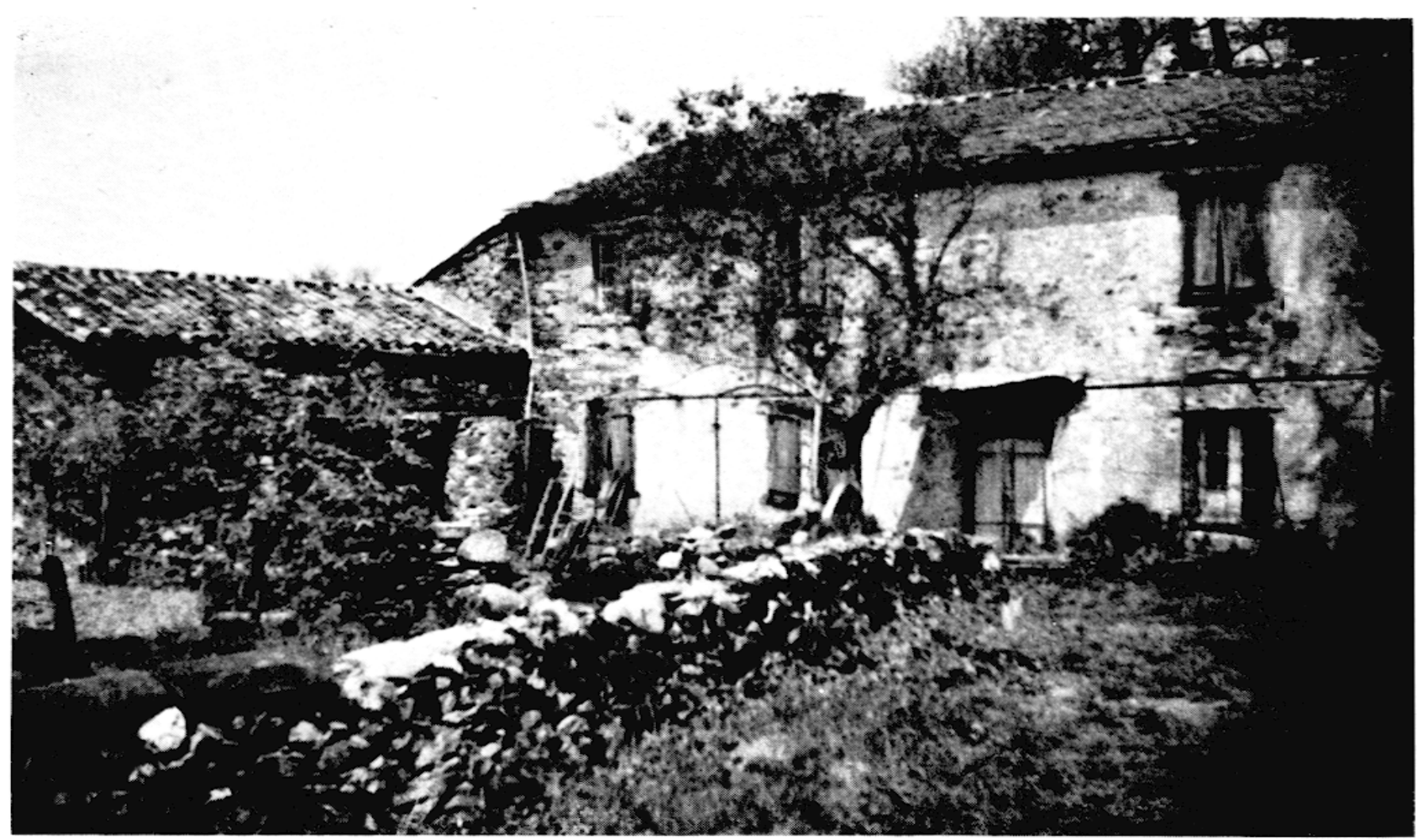

A. lne petite ferme ahandonné à Arifat.

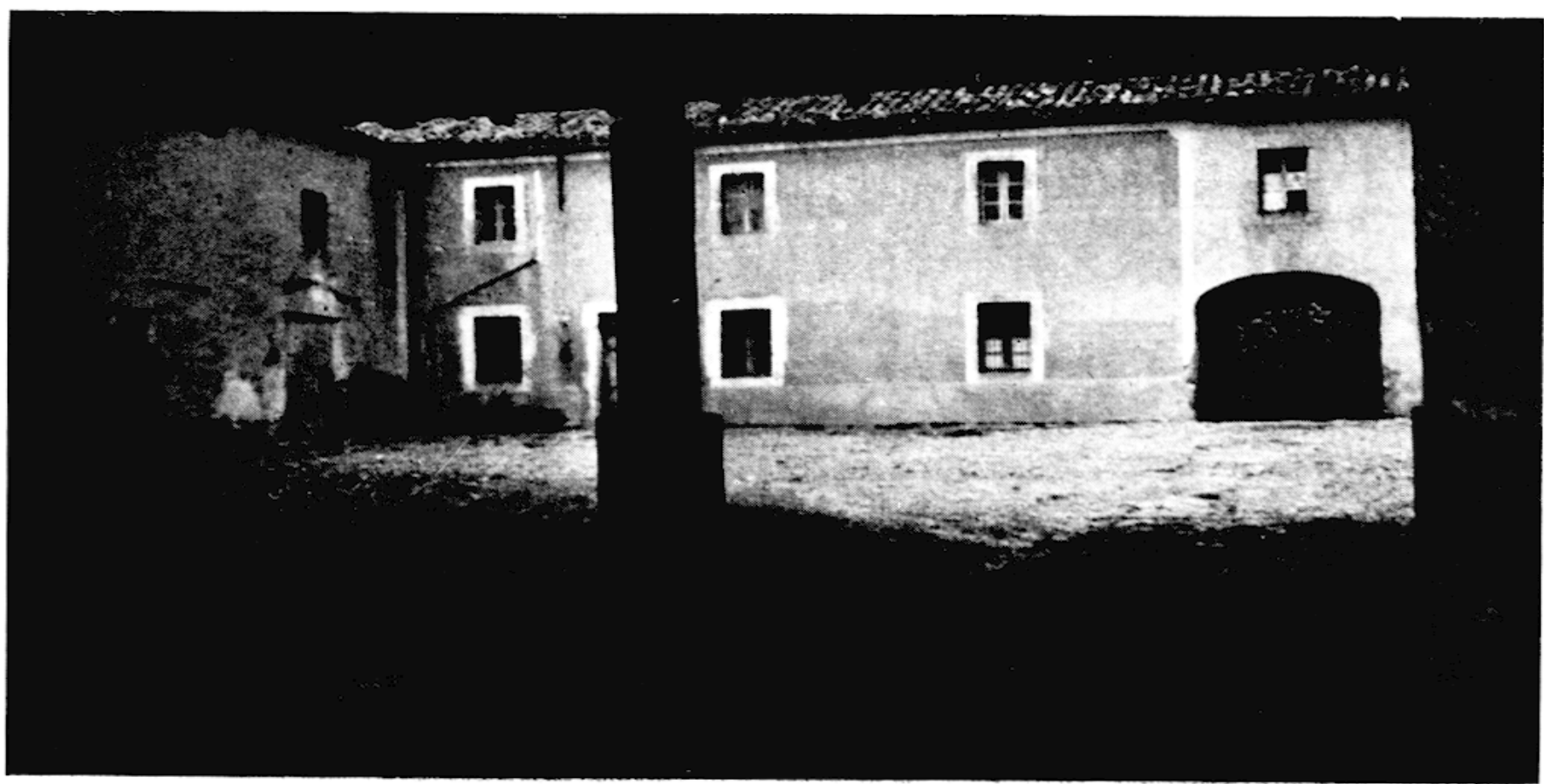

(clichess (i. Bertrand.)

13. I'n grand domaine abandonne : lastifoul, 82 hectares. 
Les quelques petites exploitations marâiehères qui se localisent, en exposition sud, sur les nappos alluriales des gorges de l'Agout présentent des caractères très différents. Elles se maintiennent grâca à des cultures délicates : asperges, fraises, tabac, plants de vigne. Les produits sont écoulés sur les marchés de Roquecourbe et de Castres. Elles sont assez prospères et contrastent avec les autres micro-exploitations qui, en pleine décadence, fournissent $24 \%$ du total des abandons.

Les petits propriétaires qui cultivent 6 à 18 ha constituent la masse de la paysannerie montredonnaise $(43,5 \%)$. A cause de leur nombre, ils représentent $41,2 \%$ des abandons, mais il $n$ 'v a que $8,8 \%$ des exploitations de cette eatégorie qui disparaissent. Cette relative stabilité est ccrtainement liée au fait qu'on se trouve en présence de l'exploitation familiale type qui fonctionne sans aide extérieure, done sans verser de salaires. L'autcensommation joue un rôle important et explique la conservation intégrale de la polyculture. Le blé se maintient, on l'échange chez le boulanger contre le pain. Cependant l'élevage hovin $y$ a pris assez nettement la première place : troupeaux de 4 à 6 bêtes, production de vean de boucherie. I es prairies artificielles l'emportent sur les prés naturels (3 à 5 ha contre 2 à 3 ha). La superficic réduite de l'exploitation ne permet pas d'entretenir un troupeau de brebis laitières. Les petits exploitants ont fait un effort pour tirer le maximum de leur exploitation dans le cadre du svstème polycultural traditionnel. Une main d'œuvre très abondante, 3 à 4 personnes actives par exploitation, avait retardé la motorisation mais, depuis $\mathbf{1 9 5 6}$, on assiste à de nombreux achats de tracteurs grâce aux prêts eonsentis par le Crédit Agricole. Or, le tracteur n'est guère rentable sur ces exploitations petites ef morcelées. Tse maintien des propriétés de 6 à 8 ha est un non-sens économique et social. Paradoxalement, elles permettent à plus de la moitié de la population montredonnaise de subsister.

Les moyens propriétaires (19 à 35 ha) passèdent $26 \%$ des exploitations. Ce sont, ici encore, des entreprises familiales qui $n$ 'emploient des salariés qu'au moment des gros travaux. Le tracteur y est rentable, mais le train de culture est souvent incomplet et le matériel à traction animale est couramment utilisé (charrues, râteaux). I a polyculture traditionnelle subsiste, cependant l'autoconsommation n'absorbe plus toute l'exploitation. L'extension récente des prairie: artificielles (6 ha en movenne contre 4 ha de prés naturels) permet d'entretenir d'assez gros troupeaux de bovins ( 8 à 9 bêtes) et on voit apparaître les premières ramades de 15 à 30 brebis laitières. Bien qu'elles soient mieux équilibrées que les petites exploitations, les 

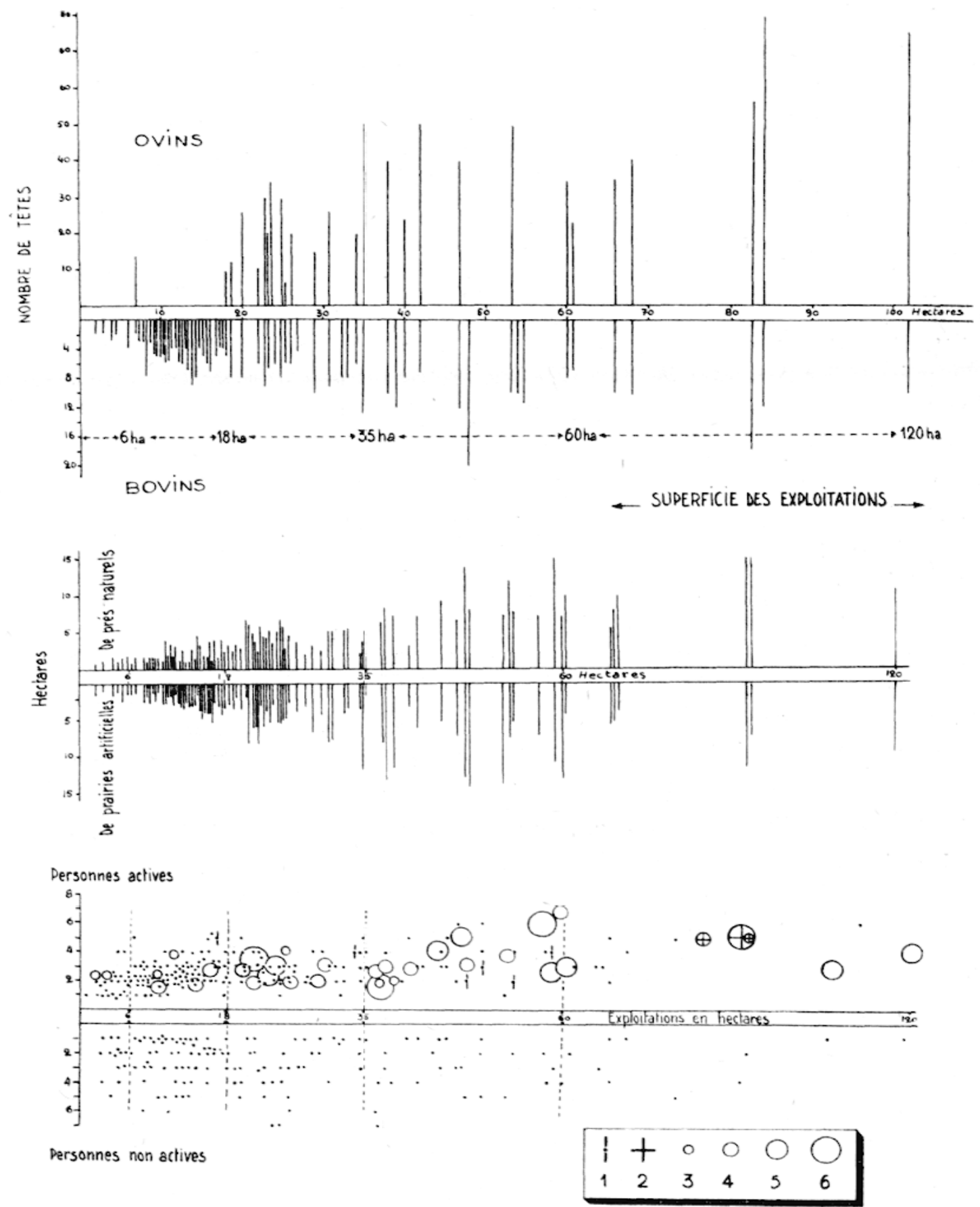

Fig. 7

Structure des exploitations du Montredonnals.

En haut, rapport ovins/bov:ns. - Au milieu, rapport prairies artificielles/prés naturels. - En bas, main-d'œuvre et charge humaine des exploitations : 1. Un salarié. - 2. Deux salariés. - 3. Un tracteur de moins de $12 \mathrm{CV}$. - 4. Un tracteur de 12 à $25 \mathrm{CV}$. - 5. Un tracteur de 25 à $28 \mathrm{CV}$. - 6. Un tracteur de plus de $28 \mathrm{CV}$. 
moyennes en possèdent la plupart des défauts. Les ventes sont irrégulières, les produits commercialisés trop variés (veaux, lait de brebis, agneaux, blé pomme de terres, fruits, volailles ete) et insuffisants en quantité comme en qualité. Ces exploitations représentent 10 à $12 \%$ des abandons totaux, ce qui montre qu'elles sont à la limite de ia rentabilité.

Dans les grandes propriétés (plus de 35 ha, $16 \%$ du total) la polyculture se commercialise sans que, pourtant, une production l'omporte nettement sur les autres. L'élevage arrive en premier lieu : 8 à 15 bovins en movenne, 50 à 80 brehis laitières. Il est surtout pratiqué sur des prés naturels non améliorés et les prairies artificiclles n'ont qu'un rôle d'appoint (par exemple 80 moutons et 12 vaches sur 16 ha de prés et 7 ha de prairies artificielles). Ise blé, par contre. est l'objet de soins attentifs et une partie de la récolte est commercialisée. Or, e'est une culture chère (chaulage, engrais) et à très faible rendement (16 à 18 q/ha.). Il y a là une sorte d'attachement presque sentimental à cette céréale qui a été autrefois, pour les paysans du Séga'a, le sumbole de l'aisance. Toutes ces cultures demandent une mécanisation poussée. Fnviron $80 \%$ des propriétaires ont un tracteur avec remornue et train de culture assez comnlet, $70 \%$ ont des voitures, $65 \%$ des moteurs « tous usages 》 (couperacines, scie. et.e). Cet écuinement a nermis de sunnrimer nresnue tous les salariés nermanents et de réduire la main-d'nuvre familiale à 2 ou 3 nersonnes. Ces orosses nronriétés font vivre, en movenne, moins de norsonnos nue les exnloitations nlus netites et le niveau de vie narât satisfaisant losins annortés à l'éruluement ménaosr. réfentionn des hôtimnnts d'habitation). Tue poureentage des ahandons. 4 i $5 \%$. $v$ est faihle.

Parmi ces gros propriétaires, on assiste à quelques efforts isolés de réaménagement, qui s'inspirent de l'exemnle des régions voisines, de la plaine comme de la montagne. Cet effort est souvent le fait d'agriculteurs venus de l'extérieur. Quelques colons d'Afrique du Nord ont dévelonné la céréaliculture dans le Bas-Montredonnais on l'élevage sur le Haut Plateau. I'un d'eux a acheté une exnloitation de 40 ha, au'il a c'ôturée et cultivéc en prairies artificielles. Il $r$ élève une vinotains de montbéliardes sélectionnées. Des pavsans de l'Averron et des Monts de Tacrune ont essavé d'implanter auelques grands êlovaọes do hrehis laitièrns mais. nmur des raisons diverses, ils ont fohnmé. T'sxpmnle neut aussi venir de certains agrienltonrs

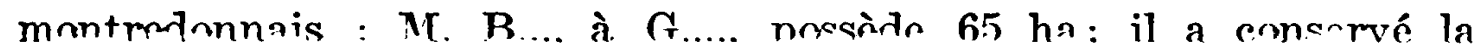
nolventtume traditinnnelle en s'rfforeant d'acernitre les rendemants des cérćales (motorisation, emploi rationnel des engrais) et des 
produits animaux (brebis sélectionnées et primées, engraissement des agneaux à l'étable, contrôle laitier); six personnes (dont un coup'e de salariés), utilisant un tracteur de $25 \mathrm{CV}$ et tout un pare de machines agricoles, arrivent à faire fonctionner cette exploitation. C'est une incontestable réussite acquis: grâce à de gros investissements, à l'appui des Services agricoles et à un travail considérable de tous les membres de la famille. Plus nombreux sont les gros propriétaires qui se sont tournés vers la semi-spécialisation animale. I, élevage bovin pour la boucherie donne d'assez bons résultats quand cn sé?cetionne les animaux et que l'on étend les cultures fourragères. Mais l'élevage ovin peut fournir davantage de satisfaction. A lexemple de la plaine castraise, certains paysans se sont orientés vers la production du mouton à viande de race charmoise. C'est ún élevage en plein air qui demande peu de main-d'œuvre et la viande de mouton se vend relativement bien. Cependant le charmois est assez fragile et supporte mal le elimat du Montredonnais. Isa municipalité de Iabessonnié a tenté, à plusieurs reprises, d'encourager l'élevage ovin laitier en ressuscitant les foires-concours du XIX' siècle. I es résultats sont assez décevants.

C. Le faire valoir indirect, source de déséquilibre. - Il ne représente que 9,4\% du total des exploitations. Cependant, il couvre $16 \%$ de la superficie totale et son rôle historique a été considérable. L'effondrement du faire-valoir indirect date de la première moitié lu $\mathrm{XX}^{\mathrm{e}}$ siècle : le métayage, par exemple, a connu une crise grave au moment de la loi Tanguy-Prigent (1946).

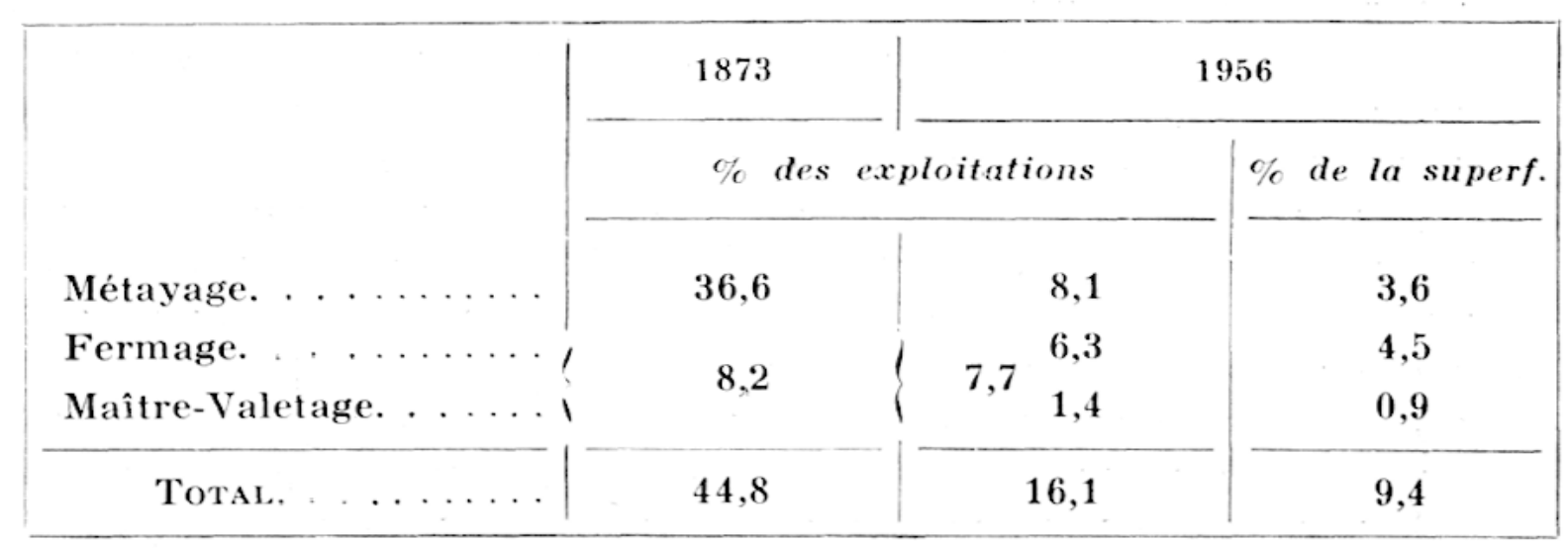

Le procès de ces contrats inégaux n'est plus à faire, surtout dans uné région agricole naturellement pauvre. Les conditions d'exploi- 
tation varient avec la surface des domaines et l'origine sociale des propriétés (26).

Les grosses exploitations indirectes sont entre les mains de l'aristocratie et de la bourgeoisie urbaine. Leur situation varie avec l'idée

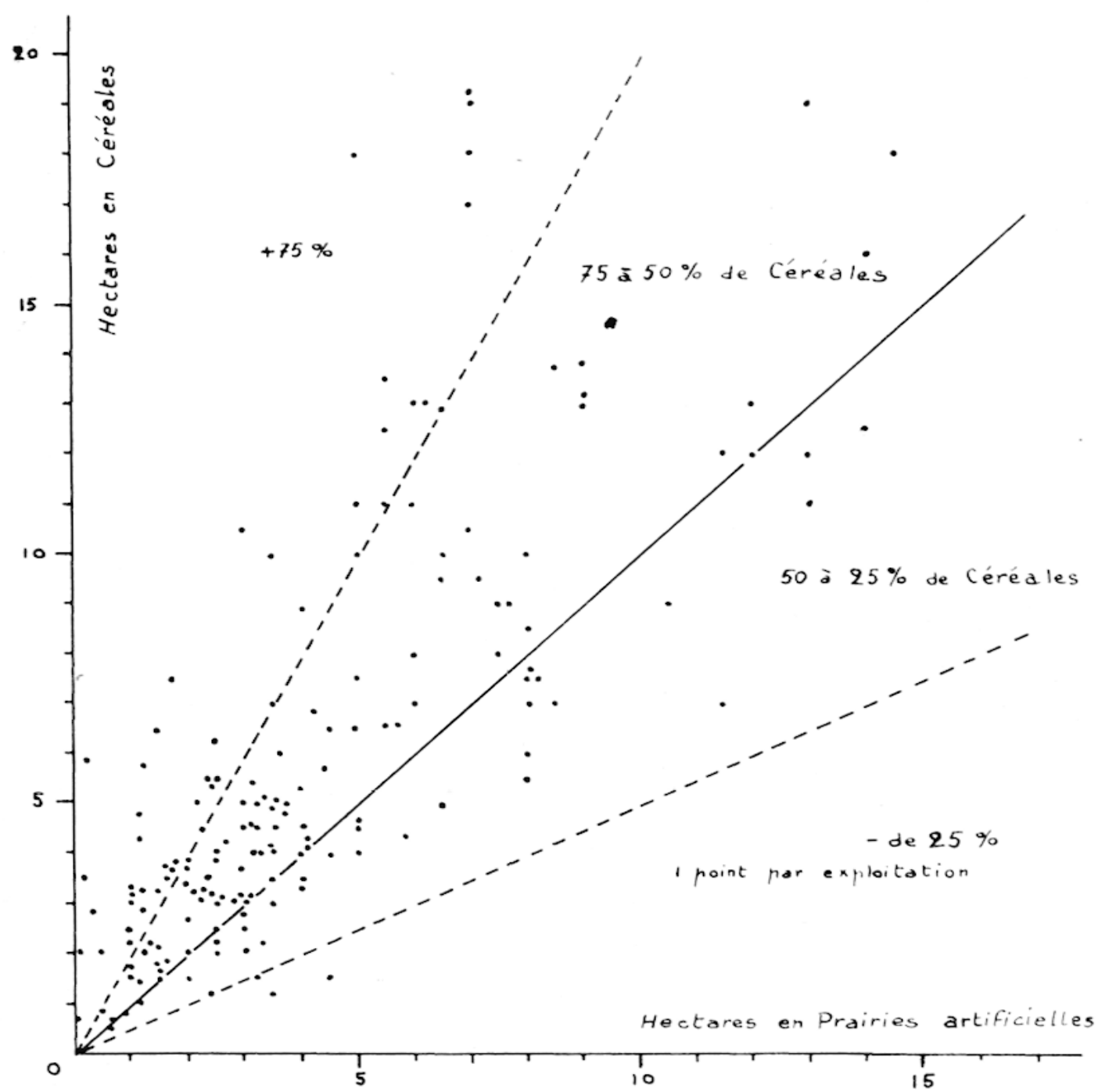

Fig. 8

La polyculture : le rapport céréales/prairies artificielles.

que se fait le propriétaire de son domaine et la quantité de capitaux qu'il veut y consacrer. L'aristocratie dédorée et la bourgeoisie plus ou moins ruinée donnent, souvent, des propriétaires absentéistes qui conservent le métayage. I a bourgeoisie industrielle et libérale est

(26) Le domicile des proprietaires terriens vivant hors du canton est le suivant: Castres $(42 \%)$, Paris $(38 \%)$, Toulouse $(18,5 \%)$, Mazamet $(1,1 \%)$, Beziers, etc. 
un peu plu dynamique; elle considère ses domaines moitié comme source de protit, moit:é comme agréabie séjour de vacances. Hille se contente souvent de ne laire, au dernier moment, que les dépenses indispensables. Les plus entreprenants sont, de loin, les gros commerçants (Ininotiers, bouchers) qui modernisent.leur propriété (mécanisation, engrais, sélection animale) et les colons nord-africains qui sont peut être les seuls à gérer leurs domaines comme des terres de rapport. Au-dessus de 60 ha on trouve des fermes et des métairies assez bien mécanisées, qui ne se différencient guère des exploitations directes équivalentes. Entre 35 et 65 ha, la situation des fermiers et des métayers est assez comparable à celle des moyens propriétairesexploitants.

Les petites exploitations indirectes (moins de 35 ha) représentent près de la moitié des propriétés en faire-valoir indirect. C'est l'aboutissement de l'exode rural vers les villes. Les propriétaires se recrutent dans les classes movennes (employés, artisans) et même parmi les ouvriers. Il faut y joindre quelques commerçants et artisans du bourg de Montredon. Tous manquent de capitaux, leurs terres sont mal cultivées ear ils lésinent sur les achats d'engrais et de semence. Il leur est de plus en plus difficile de trouver des métavers. En 1956, aucune exploitation indirecte de moins de 35 ha $n$ 'était motorisée et on $y$ maintenait la polyculture traditionnelle. Dans la plupart des cas, on doit considérer la propriété indirecte comme une forme de parasitisme (27).

2. Les limites du réaménagement agricole. - La reconversion de l'ayriculture reste à faire. En effet, on ne peut parler que de réaménagements partiels. La société montredonnaise reste tributaire du système polycultural traditionnel, l'agriculture étant considérée comme un genre de vie et non comme une source de proflt.

1. L'avenir de l'agriculture. - L'examen des différentes catégories sociales permet de distinguer, assez grossièrement, trois groupes d'exploitations : celles qui paraîssent condamnées, celles qui sont bénéficiaires et celles qui sont déséquil ‘brées. Ces constatations ressortent directement des analyses précédentes. Les exploitations condamnées représentent 16 à $18 \%$ du total. Ce sont les micro-propriééés de moins de 6 ha et toutes les exploitations indirectes de moins cle

(27) Il s'agit là d'un fait récent. Jusque vers 1930 , la bourgeoisie terrienne a inv'sti des capitalx et a ćté à l'origine de certain progrès. Cela a été, par exemple, le cas de Bernard Lavergne, qui a réfléchi aux servitures de l'agriculture des terrains pauvres (7), et a tenté quelques améliorations (assolements, engrais, reboisement). 
35 ha. En 1956, elles fournissaient $30 \%$ des abandons totaux. L'émigration est le seul remède. A l'oppasé, il existe 15 à $16 \%$ d'exploitations bien équilibrées; on doit $\mathrm{y}$ inclure les exploitations directes

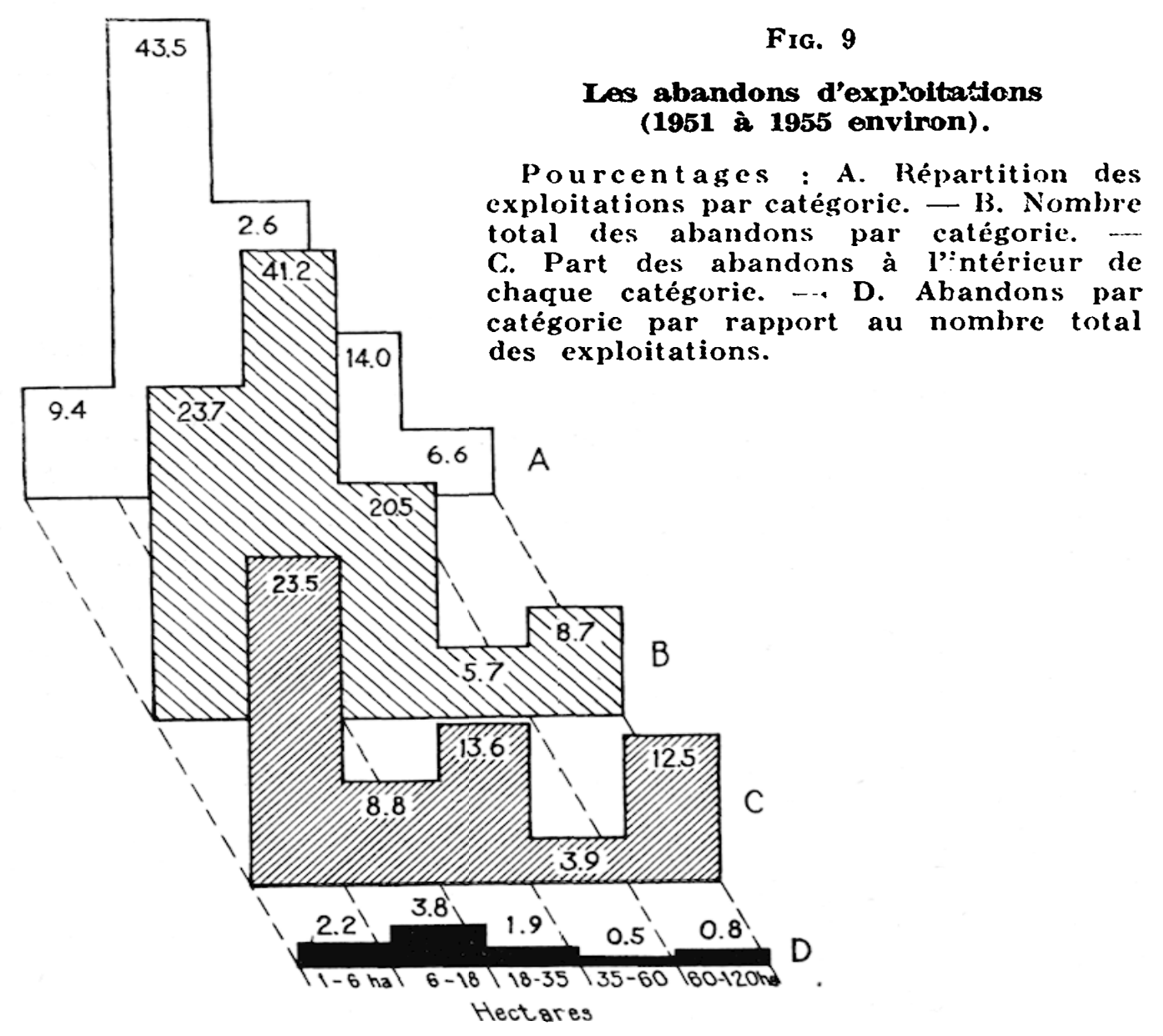

de plus de 35 ha et la plupart des domaines en faire-valoir indirect de plus de 60 ha. Reste la masse des petits et moyens agriculteurs (propriétaires de 6 à 35 ha, métayers et fermiers cultivant entre 35 et $60 \mathrm{ha}$ ). Ils représentent 56 à $58 \%$ du total des exploitants. Leur existence est à l'origine de la crise traversée par la société montredonnaise. Seule une aide extérieure soutenue, hors de proportion avec les résultats économiques que l'on peut en espérer, pourrait assurer le maintien des plus favorisés d'entre eux. La seule tentative intéressante avait été l'implantation d'industries minières. Elle s'est avérée inopérante et même néfaste (28). Les autres remèdes envisagés ne sont que $d$ es palliatifs (création de « gîtes ruraux », dé-

(28) G. Bratrand (4). 
veloppement du tourisme et installation de colonies de vacances (29). En réalité, c'est le système de culture et la mentalité des paysans qu'il faudrait faire évoluer. Lue maintien de la polyculture est un facteur indispensable de stabilité, mais le secteur commercialisé devrait être développé, la production animale devrait devenir le centre de tout le système agricole (extension des prairies artificielles et des cultures fourragères aux dépens du blé). L'obstacle le plus redoutable est le manque d'organisation de la profession agricole. Mais la coopération agricole, le remembrement des exploitations ne sont pas pour demain. D'ailleurs, le reboisement a déjà entraîné le Plateau de Montredon dans une évolution irréversible.

B. Le problème du reboiseme'nt. - La création du Fonds F'orestier National a déterminé un vigoureux essor du reboisement dans le Sud du Ségala tarnais. Les plantations de pins sont en effet, le seul moyen de valoriser les vastes surfaces de landes, de taillis et de friches. Le reboisement a commencé assez tard dans le Montredonnais. Jusqu'à ces derniers temps, ce sont surtout les propriétaires bourgeois qui ont reboisé. En effet, l'exploitation indirecte est de moins en moins rentable et il est difficile de trouver des métayers. Par contre, le F.F.N. offre des avantages considérables (dégrèvements d'impôts, plants gratuits etc), si bien que l'exploitation reboisée représente un capital supérieur à celui de l'exploitation en culture. Comme il s'agit de plantations de rappont, on ne reboise pas les landes et les taillis, mais les meilleures terres. Il ne faut pas sousestimer le choe psychologique qu'un tel événement provoque sur les exploitants voisins. Certains gros propriétaires reboisent dans les mêmes conditions lorsqu'ils émigrent. Quand ils restent sur leur exploitation ils se contentent de «planter» quelques parcelles de landes ou de friches. Le cas des petits propriétaires est différent. Lorsqu'ils s'en vont, ils conservent leurs terres dans l'espoir de reboiser. $L$ 'expérience montre qu'ils $n$ 'y parviennent presque jamais faute de capitaux et de soutien. Jusqu'à présent, le reboisement a eu des conséquences plutôt défavorables. Il empêche le remembrement des exploitations et il s'accompagne d'un certain découragement de la part des paysans qui voient leur exploitaticn transformée en clairière. Toute la société, déjà fragile, en est ébranlée. Il peut fournir une nouvelle richesse mais, avant que la forêt soit exploitable, il y a une coupure d'une trentaine d'années (30). Le reboisement n'est en somme qu'une forme insidieuse du renoncement.

(29) Peyroutet (8).

(30) Cette ressource risque d'ailleurs d'échapper partiellement à la population locale comme c'est le cas sur le Plateau d'Anglès où l'exploitation de la foret est le fait dentrepreneurs et d'ouvriers etrangers î la région. Voir Peynouter (8). 


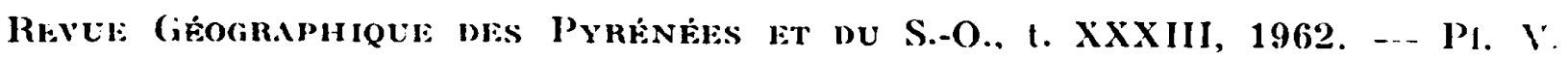

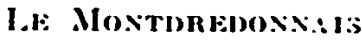

A. Type de pavsanne allx Comhettes. Outillag: archaïque (la mousso).
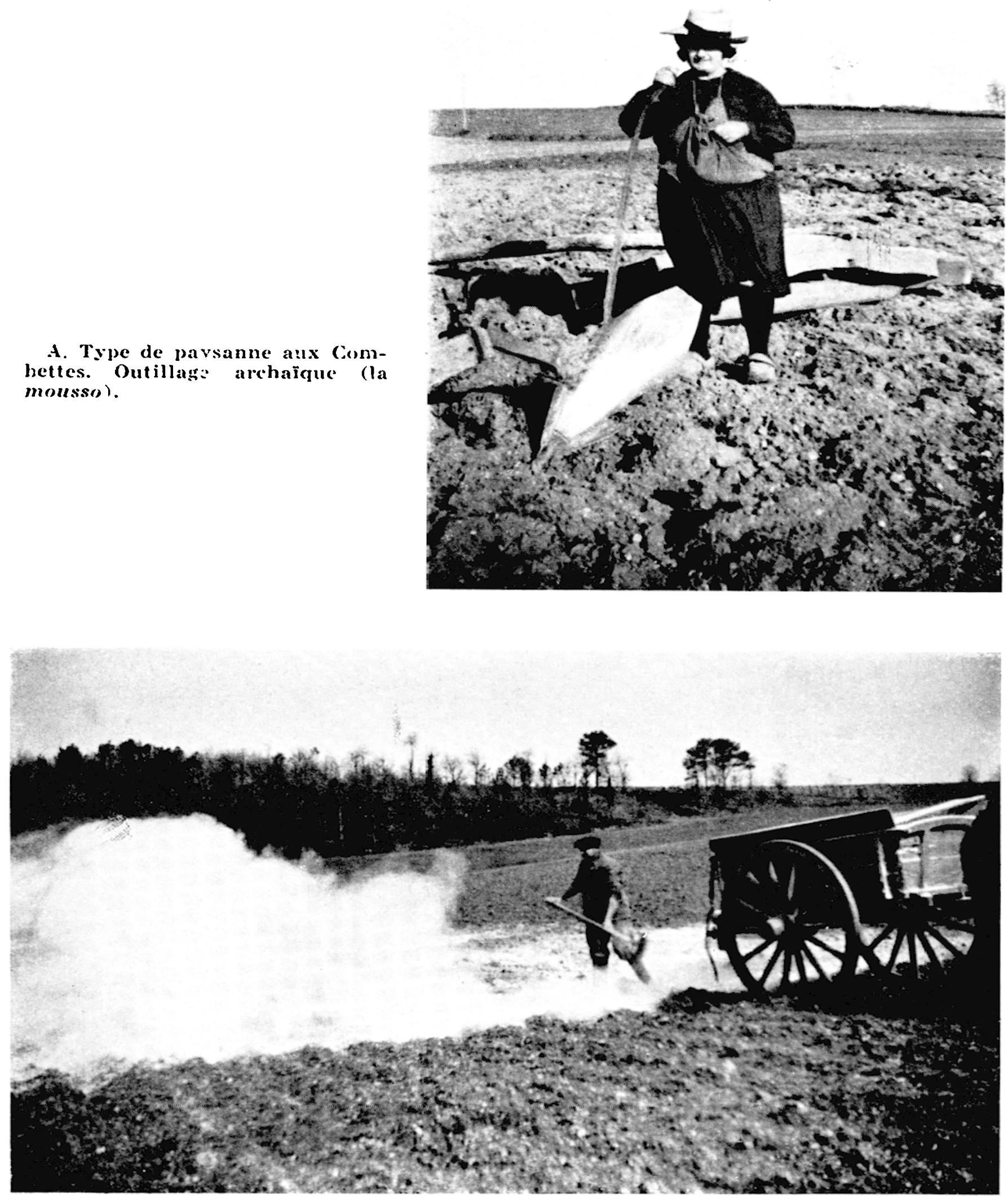

(cliche's (;. Bertrand.)

B. I.'indispensable chaulage. 


\section{BIBLIOGRAPHIE SOMMAIRE}

1. I). Favcher, Géographie agraire. Types de culture. Paris, Libr. de Médicis, $1951,382 \mathrm{p}$.

2. D. Faucher, Le paysan et la machine. Paris, Ed. de Minuit, 1954.

3. D. Favcher, La vie rurale vue par un géographe. Toulouse, Inst. de Géogr. de la Fac. des Lettres, 1962.

4. G. Bentrand, Un type d'implantation industrielle en milieu rural : les mines de Montredon-Labessonnié (Tarn). Rev. géogr. des Pyrénées, I. XXX, 1959, fasc. II, pp. 169-178.

5. G. Bertrand, Les traits morphologiques originaux du Plateau de Montredon-Labessonnié (Sud-Ouest du Massif Central). Rev. géogr. Pyrénées, t. XXXI, 1960, fase. III, pp. 277-293.

6. F. Bousquet, Montredon. Essai d'histoire d'une commune de France, des origines à la Révolution. Thèse Lettres, Toulouse, 1926, 560 p.

7. B. Lavergne, L'agriculture des terrains pauvres. Manuel pratique d'agriculture. 1882, $301 \mathrm{p}$.

8. Peyroutet, Enquête concernant l'agriculture en montagne dans le département du Tarn. Chambre d'Agriculture du Tarn, Session du 9 juin 1960, pp. 35-52.

9. G. DE Rouvirle, L'association sylvo-pastorale. Extrait du Bulletin de la Fédération Française d'Economic Alpestre. 